\title{
INCIDENCE OF DEFECTS IN VISUAL FUNCTION IN CHILDREN AND ADULTS
}

\author{
BY \\ ARNOLD SORSBY, B. BENJAMIN, AND JOHN YUDKIN \\ London
}

Examination of the eyes in the course of routine inspections in the School Medical Service is generally confined to establishing the presence of any obvious external eye disease, squint, and subnormal visual acuity. In different school returns some 20 to 30 per cent. of children are found to have defective visual acuity on school-leaving age, and the correction of refractive errors is, in fact, the largest aspect of the care of the eyes provided by the School Medical Service. That a certain number of boys, probably as much as 8 per cent., have some colour defect has been established by many special studies. The fact that some 1.5 per cent. of children show manifest squint raises the possibility that many more suffer from minor muscle imbalance. Since defects in colour vision and muscle balance exclude adults from certain specified occupations, and may constitute a serious handicap in others where no definite standards are laid down, it seems worth while to determine the extent of anomalies in visual function other than central visual acuity. Two parallel investigations have been undertaken, one in children at school-leaving age and the other in adults working as engineers in the Post Office.

The investigation on school children was carried out at West Ham during the years 1948-49; in all 654 children aged 12 to 14 years were examined. The investigation at the Post Office, made during 1950, concerned 501 men aged 21 to 40 years, and was carried out at the Personnel Department of the Post Office. This is not altogether a random sample of adult men, for certain visual standards-not very exacting-have to be satisfied by candidates for admission to the Post Office Service. Both.series were re-investigated in 1953 to assess efficiency at work against the ocular findings.

\section{Functions Tested and Methods Used}

Visual acuity with and without glasses was taken in all cases; where glasses were needed these were worn in assessing the following functions: accommodation, convergence, muscle balance, binocular vision, colour vision, and dark adaptation. In children haemoglobin readings were carried out in addition, since both dark adaptation and haemoglobin may be affected by nutrition. The methods employed are given in Appendix I.

Findings in SchoOl Children

Basic Data.-These are summarized in Table I.

(a) Visual Acuity without Glasses.-Some 29 per cent. of children showed visual acuity of less than

TABLE I

INCIDENCE OF ANOMALIES RELATED TO VISUAL ACUITY IN CHILDREN

\begin{tabular}{|c|c|c|c|c|c|c|c|c|c|c|c|c|}
\hline \multirow{2}{*}{\multicolumn{4}{|c|}{ Function }} & \multirow{3}{*}{$\begin{array}{l}\text { Criteria of } \\
\text { Normality }\end{array}$} & \multicolumn{8}{|c|}{ Unaided Visual Acuity (assessed by the worse eye) } \\
\hline & & & & & \multicolumn{2}{|c|}{$\begin{array}{c}6 / 4-6 / 6 \\
(462 \text { cases })\end{array}$} & \multicolumn{2}{|c|}{$\begin{array}{c}6 / 9-6 / 18 \\
(102 \text { cases })\end{array}$} & \multicolumn{2}{|c|}{$\begin{array}{l}6 / 24 \text { or worse } \\
\text { (90 cases) }\end{array}$} & \multicolumn{2}{|c|}{$\begin{array}{c}\text { Total } \\
\text { (654 cases) }\end{array}$} \\
\hline & & & & & No. & $\%$ & No. & $\%$ & No. & $\%$ & No. & $\%$ \\
\hline Convergence & .. & . & .. & $5 \cdot 0-8 \cdot 5 \mathrm{~cm}$ & 456 & $5 \cdot 7$ & 100 & $14 \cdot 0$ & 81 & $9 \cdot 9$ & 637 & $7 \cdot 5$ \\
\hline Accommodation & . & . & . & $12 \mathrm{~cm}$. or less & 457 & $6 \cdot 1$ & 102 & $16 \cdot 7$ & 78 & $16 \cdot 7$ & 637 & $9 \cdot 1$ \\
\hline \multirow{4}{*}{ Heterophoria } & \multirow{2}{*}{ Vertical } & \multicolumn{2}{|c|}{ Near } & $0- \pm \frac{1}{2} \Delta$ & 448 & $2 \cdot 5$ & 97 & $5 \cdot 2$ & 79 & $10 \cdot 1$ & 624 & $3 \cdot 8$ \\
\hline & & \multicolumn{2}{|c|}{ Distance } & $0- \pm \frac{1}{2} \Delta$ & 447 & $2 \cdot 0$ & 95 & $10 \cdot 5$ & 80 & $7 \cdot 5$ & 622 & $4 \cdot 0$ \\
\hline & \multirow{2}{*}{ Lateral } & \multicolumn{2}{|c|}{ Near } & $0- \pm 4 \mathrm{D}$ & 448 & $5 \cdot 1$ & 97 & $19 \cdot 6$ & 79 & $20 \cdot 3$ & 624 & $9 \cdot 3$ \\
\hline & & \multicolumn{2}{|c|}{ Distance } & $0- \pm 4 \mathrm{D}$ & 446 & $2 \cdot 5$ & 95 & $14 \cdot 7$ & 79 & $7 \cdot 6$ & 620 & $5 \cdot 0$ \\
\hline \multicolumn{2}{|l|}{ Binocular Vision } & . & . & $\begin{array}{c}\text { Any grade of stereo- } \\
\text { scopic vision }\end{array}$ & 457 & $1 \cdot 1$ & 102 & $2 \cdot 0$ & 87 & $14 \cdot 9$ & 646 & $3 \cdot 1$ \\
\hline \multicolumn{2}{|l|}{ Colour Vision } & $\cdots$ & .. & $\begin{array}{c}\text { Normal to the Ishihara } \\
\text { test.. }\end{array}$ & 455 & $10 \cdot 8$ & 101 & $11 \cdot 9$ & 86 & $10 \cdot 5$ & 642 & $10 \cdot 9$ \\
\hline \multicolumn{2}{|l|}{ Dark Adaptation } & . & .. & $2 \cdot 5-3 \cdot 1$ log. $\mu \mu 1$. & 453 & $4 \cdot 0$ & 98 & $9 \cdot 2$ & 84 & $11 \cdot 9$ & 635 & $5 \cdot 8$ \\
\hline Haemoglobin & . & .. & $\ldots$ & At least $12 \mathrm{~g}$. per $\mathrm{ml}$. & 453 & $3 \cdot 5$ & 100 & $4 \cdot 0$ & 88 & $1 \cdot 1$ & 641 & $3 \cdot 3$ \\
\hline
\end{tabular}


$6 / 6$ in one or both eyes. The separate distributions for age and sex did not differ significantly from the distribution of the group as a whole, nor was there any significant difference between right and left eyes. If visual acuity was good in one eye it was generally also good in the other-the correlation between right and left (on scaling $6 / 24$ as $0.25,6 / 18$ as 0.33 etc.) is +0.83 .

(b) Accommodation.-There were no significant differences with age or sex. Each eye was tested separately and there was close agreement between right and left eyes in individual children. Some 74 per cent. were able to accommodate at 9 to $11 \mathrm{~cm}$., and an additional 8 per cent. at an even closer range.

(c) Convergence.-There were no significant differences with age or sex. Some 52 per cent. of children could converge to a distance of $5.5 \mathrm{~cm}$., and relatively few were unable to converge to a distance less than $9 \mathrm{~cm}$.

(d) Muscle Balance.-The incidence of heterophoria was determined for both near and distance and for lateral and vertical balance. Orthophoria was found to be not as exceptional as is generally believed. In fact, both for near and for distance the values for orthophoria were the highest observed: 46 and 66 per cent. respectively. Marked degrees of heterophoria were uncommon. Assessment of vertical imbalance gave the expected high incidence of orthophoria: 96 per cent. for both near and distance. No age or sex variations were seen in lateral or vertical imbalances. There was a statistically significant (though not strong) association between near and distance readings: vertical $r=+0 \cdot 35$, lateral $r=+0 \cdot 46$. The measurements for lateral distance balance were made separately for right and left eyes. The co-efficient of correlation between the measurement of the two eyes was very high, $+0 \cdot 89$.

(e) Binocular Vision.-No variations were seen with age or sex; only $3 \cdot 1$ per cent. of children had no stereoscopic vision. The degree of stereoscopic vision was determined in $\mathbf{4 2 5}$ children; of these only 77 were found. to have stereoscopic vision less than Grade 5 on the Livingston scale.

(f) Colour Vision.-No age variation of any statistical significance was observed, but the usual sex difference was found: some 85 per cent. of boys and 94 per cent. of girls were normal. (Amongst boys red defect was present in 2 per cent., green defect in 5.5 per cent. and anomalous colour vision was seen in 7.8 per cent.; the corresponding percentages for girls were $0 \cdot 0,0 \cdot 7$, and $5 \cdot 0$ ).

(g) Dark Adaptation.-No age or sex variation was seen. Most children gave readings between $2 \cdot 7$ and $3 \cdot 1 \log \mu \mu l$. on the Crookes adaptometer. Readings lower than 2.7 were observed in 2.2 per cent. of cases, and readings higher than 3.1 in 5.8 per cent.

(h) Haemoglobin.-As an adjunct to readings for dark adaptation haemoglobin determinations were carried out. There were no significant age and sex variations. The distribution was mainly within the range of 11 to $16 \mathrm{~g}$. per cent., the peak being between 13 and $14 \mathrm{~g}$. per $100 \mathrm{~mm}$. There was considerable variation, the coefficient of variation being $8 \cdot 3$ per cent.

Criteria of Normality.-These are shown in Table I against each function. They were assessed on clinical grounds and generally agreed with those derived from inspection of the curves of distribution of the actual findings, except that the assumed standard of normality was perhaps rather too strict for accommodation and for dark adaptation, and perhaps too lenient for convergence. Visual acuity was regarded as normal if the unaided vision in each eye was $6 / 6$ or better.

INCIDENCE of Defects.-As Table I shows, each function tested separately gave a proportion of defectives. The data were not quite complete in all cases and the incidence of defect-by the arbitrary criteria employed here-varied with different functions.

The incidence of anomalies of the different visual functions is inconsiderable in children with normal visual acuity, and considerably higher in those whose unaided vision is less than normal in one or both eyes. A striking but expected exception is the incidence of colour vision. Correction for visual acuity does not apparently compensate the excess of defects in those with initially subnormal vision, for the tests were carried out with correcting glasses when worn, and only exceptionally did these give vision of less than $6 / 6$ in each eye.

Proportion of Normal Children.-Confining attention to the 553 cases out of the 654 in which records were available for all the functions, Table II (opposite) shows that about 75 per cent. of all cases have normal visual acuity, and that only about 70 per cent. of these are normal when other visual tests are also considered. If all visual functions are considered only some 52 per cent. of the school population are normal. 
It may also be noted that of the 139 children with visual acuity below normal, some 47 per cent. were normal in every other visual function.

TABLE II

CHILDREN NORMAL ON SCREENING TESTS

\begin{tabular}{|c|c|c|c|c|c|}
\hline \multirow{2}{*}{\multicolumn{2}{|c|}{ Visual Acuity }} & \multicolumn{2}{|c|}{$\begin{array}{l}\text { Normal } \\
\text { (414 children) }\end{array}$} & \multicolumn{2}{|c|}{$\begin{array}{c}\text { Subnormal } \\
\text { (139 children) }\end{array}$} \\
\hline & & No. & $\%$ & No. & $\%$ \\
\hline Functions & $\begin{array}{lllllllll}1 & & & & & & & \\
1 & 2 & & & & & & & \\
1 & 2 & 3 & & & & & & \\
1 & 2 & 3 & 4 & & & & & \\
1 & 2 & 3 & 4 & 5 & & & \\
1 & 2 & 3 & 4 & 5 & 6 & & \\
1 & 2 & 3 & 4 & 5 & 6 & 7 & & \\
1 & 2 & 3 & 4 & 5 & 6 & 7 & 8 & \\
1 & 2 & 3 & 4 & 5 & 6 & 7 & 8 & 9\end{array}$ & $\begin{array}{l}389 \\
365 \\
356 \\
351 \\
337 \\
333 \\
328 \\
298 \\
288\end{array}$ & $\begin{array}{l}94 \cdot 0 \\
88 \cdot 2 \\
86 \cdot 0 \\
84 \cdot 8 \\
81 \cdot 4 \\
80 \cdot 4 \\
79 \cdot 2 \\
72 \cdot 0 \\
69 \cdot 6\end{array}$ & $\begin{array}{r}125 \\
103 \\
96 \\
93 \\
80 \\
79 \\
79 \\
70 \\
65\end{array}$ & $\begin{array}{l}89 \cdot 9 \\
74 \cdot 1 \\
69 \cdot 1 \\
66 \cdot 9 \\
57 \cdot 6 \\
56 \cdot 8 \\
56 \cdot 8 \\
50 \cdot 4 \\
46 \cdot 8\end{array}$ \\
\hline
\end{tabular}

Key to Functions

1. Convergence.

2. Accommodation.

5. Heterophoria, lateral near

3. Heterophoria, vertical near. 8. Binocular vision.

4. Heterophoria, vertical distance. 9. Dark adaptation.

Gross Frequency of Anomalies.-It is known from Table II that in children with unaided normal visual acuity the chances are two to one that other functions will be normal too. Actually it is exceptional for a child with normal vision to have more than one abnormality, and no child in this group had more than three anomalies.

Amongst those whose visual acuity was subnormal without glasses the chances were even that other functions would be subnormal. The gross incidence of other defects was rather higher and more broadly distributed than in children with normal vision.

It may be noted that no child was abnormal in all the visual functions.
CoRrelations.-The inter-correlation between pairs of characteristics was tested. No strong associations were found but some statistically significant though weak associations are shown in Table III.

TABLE III

STATISTICALLY SIGNIFICANT ASSOCIATIONS IN CHILDREN

\begin{tabular}{|c|c|c|c|c|c|}
\hline \multicolumn{4}{|c|}{ Defects Associated } & $P\left(\chi^{2}\right)$ & $\begin{array}{l}\text { Tschuprow's } \\
\text { Coefficient }\end{array}$ \\
\hline \multirow{7}{*}{$\begin{array}{l}\text { Visual } \\
\text { Acuity } \\
\text { and }\end{array}$} & \multicolumn{2}{|c|}{ Accommodation } & .. & $<0.01$ & $0 \cdot 12$ \\
\hline & \multirow{4}{*}{ Heterophoria } & \multirow{2}{*}{ Vertical } & Near & $<0.01$ & $0 \cdot 14$ \\
\hline & & & Distance & $<0.01$ & $0 \cdot 15$ \\
\hline & & I 1 & Near & $<0.01$ & $0 \cdot 28$ \\
\hline & & & Distance & $<0.01$ & $0 \cdot 17$ \\
\hline & \multicolumn{2}{|c|}{ Binocular Vision } & . & $<0.01$ & $0 \cdot 21$ \\
\hline & \multicolumn{2}{|c|}{ Dark Adaptation } & . & $<0.02$ & 0.09 \\
\hline \multicolumn{4}{|c|}{ Convergence and Heterophoria, lateral near } & $<0.01$ & 0.09 \\
\hline
\end{tabular}

No statistically significant association was found between dark adaptation and haemoglobin levels. Dark adaptation was subnormal in 36 out of 602 children with normal haemoglobin levels and in one case out of 21 with subnormal levels (exact probability method of Fisher gave $p=0.64$ ).

\section{Findings in Adult Men}

BASIC DATA.-These are summarized in Table IV.

(a) Visual Acuity without Glasses.-Four age groups were considered: $21-24,25-30,31-34$, and $35-40$ years. The four groups taken as a whole show visual acuity of $6 / 6$ or more in the worse eye in some

TABLE IV

INCIDENCE OF ANOMALIES RELATED TO VISUAL ACUITY IN ADULTS

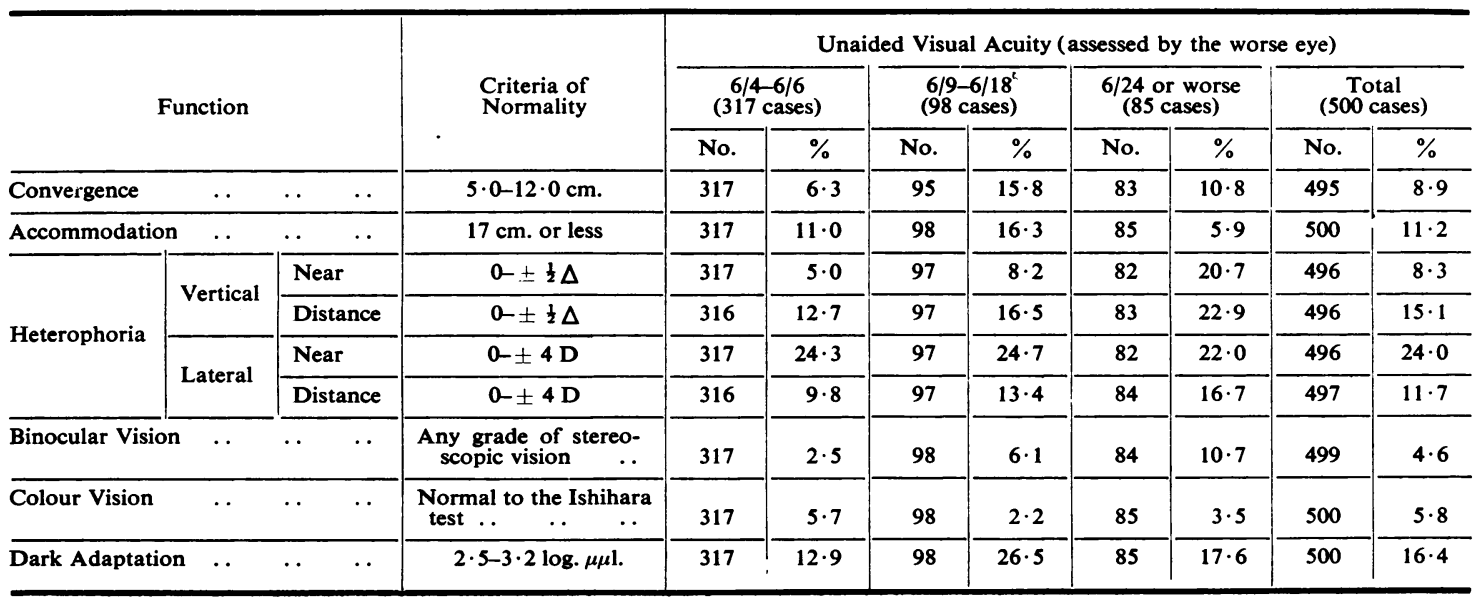


63 per cent. There was, however, a statistically significant variation with age, the incidence of full visual acuity being $68 \cdot 6,66 \cdot 7,56 \cdot 5$, and $54 \cdot 2$ per cent. in the four age groups. The correlation coefficient between right and left eye (scaling 6/24 as $0 \cdot 25,6 / 18$ as $0 \cdot 33$, etc.) is +0.65 .

(b) Accommodation.-The range of accommodation also varied with age. In the four groups aged between 21 and 40 years, ability to accommodate to $14 \mathrm{~cm}$. or less was present in some 77 per cent., 72 per cent., 51 per cent., and 33 per cent. In the first age group (21-24 years) some 4 per cent. could not accommodate at $17 \mathrm{~cm}$. or less, and in the three succeeding age groups this percentage rose to 8,13 , and 27 per cent.

(c) Convergence.-There was no significant difference between the different ages. The modal value was $5.5 \mathrm{~cm}$. No individual could converge to less than that, and only 3.4 per cent. failed to converge to $14 \mathrm{~cm}$.

(d) Muscle Balance.-The distribution for lateral balance showed no significant variations with age. Orthophoria itself was not common (about 20 per cent. for near, and about 27 per cent. for distance). If, however, values ranging from 0 to $\pm 4 \triangle$ are taken as normal, about 76 per cent. were normal for near, and 88 per cent. for distance. Vertical orthophoria was observed in 92 per cent. for near and in 85 per cent. for distance. No age variations were seen.

(e) Binocular Vision.-Here, too, no age variations were seen; about 95 per cent. showed stereoscopic vision, 80 per cent. giving readings between 5 and 10 on the Livingston scale.

( $f$ ) Colour Vision.-The incidence of colour defect was 5.8 per cent.

(g) Dark Adaptation.-There was a perceptible deterioration in adaptation with advancing age. At 21 to 24 years $12 \cdot 3$ per cent. showed a reading of $3 \cdot 3 \log \mu \mu \mathrm{l}$. or higher, and at 35 to 40 years the corresponding percentage was $26 \cdot 1$.

(h) Haemoglobin.-No examinations were made.

Criteria of Normality.-These are shown in Table IV against each function. As in the children they were assessed on clinical grounds and generally agreed with those derived from the distribution of the actual findings. With three functions-visual acuity, accommodation, and dark adaptationcapacity varied with age, but the criteria for normality shown in Table IV were those found for the group as a whole.

It will be noted that the same standards were used for adults as for children for visual acuity, muscle

balance, binocular vision, and colour vision, and that lower standards for adults were employed for convergence, accommodation, and dark adaptation.

INCIDENCE OF DEFECTS.-The adults, like the children, showed a considerable incidence of defects in functions other than central visual acuity (Table IV).

The anomalies observed for the different categories of unaided visual acuity are also shown in Table IV. As in the children, the incidence of anomalies was almost consistently higher in those with defective visual acuity than in those with good vision.

Proportion of Normal Adults.-Table V, covering 493 cases with complete records, shows that 316 men with normal visual acuity had a total incidence of $55 \cdot 1$ per cent. of other defects, so that the $64 \cdot 1$ per cent. of the total with normal vision was reduced to 28.8 per cent. with completely normal ocular functions. Only a little more than one quarter of adults were therefore normal by all the criteria used here. It may also be noted that of 177 adults with visual acuity below normal, $31 \cdot 1$ per cent. were normal in every other respect.

TABLE V

PROPORTION OF ADULTS NORMAL ON SCREENING TESTS

\begin{tabular}{|c|c|c|c|c|c|}
\hline \multirow{2}{*}{\multicolumn{2}{|c|}{ Visual Acuity }} & \multicolumn{2}{|c|}{$\begin{array}{c}\text { Normal } \\
\text { (316 persons) }\end{array}$} & \multicolumn{2}{|c|}{$\begin{array}{l}\text { Subnormal } \\
\text { (177 persons) }\end{array}$} \\
\hline & & No. & $\%$ & No. & $\%$ \\
\hline Functions & $\begin{array}{lllllllll}1 & & & & & & & & \\
1 & 2 & & & & & & & \\
1 & 2 & 3 & & & & & & \\
1 & 2 & 3 & 4 & & & & & \\
1 & 2 & 3 & 4 & 5 & & & \\
1 & 2 & 3 & 4 & 5 & 6 & & \\
1 & 2 & 3 & 4 & 5 & 6 & 7 & & \\
1 & 2 & 3 & 4 & 5 & 6 & 7 & 8 & \\
1 & 2 & 3 & 4 & 5 & 6 & 7 & 8 & 9\end{array}$ & $\begin{array}{l}297 \\
264 \\
248 \\
225 \\
176 \\
167 \\
165 \\
159 \\
142\end{array}$ & $\begin{array}{l}94 \cdot 0 \\
83 \cdot 5 \\
78 \cdot 5 \\
71 \cdot 2 \\
55 \cdot 7 \\
52 \cdot 8 \\
52 \cdot 2 \\
50 \cdot 3 \\
44 \cdot 9\end{array}$ & $\begin{array}{r}152 \\
142 \\
124 \\
110 \\
87 \\
83 \\
81 \\
77 \\
55\end{array}$ & $\begin{array}{l}85 \cdot 9 \\
80 \cdot 2 \\
70 \cdot 1 \\
62 \cdot 1 \\
49 \cdot 2 \\
46 \cdot 9 \\
45 \cdot 8 \\
43 \cdot 5 \\
31 \cdot 1\end{array}$ \\
\hline
\end{tabular}

Key to Functions

1. Convergence.

2. Accommodation.

3. Heterophoria, vertical near.

5. Heterophoria, lateral near.

6. Heterophoria, lateral distance.

7. Binocular vision.

8. Colour vision.

4. Heterophoria, vertical distance. 9. Dark adaptation.

Gross Frequency of Anomalies.-Amongst those with normal visual acuity nearly one-quarter had anomalies in two or more other visual functions. The corresponding proportion amongst those with abnormal visual acuity was nearly one-third.

CoRrelations.-The inter-correlation between pairs of characteristics was tested from Table IV and similar cross tabulations. No strong associations were found, but some statistically significant though weak associations are shown in Table VI (opposite). 
TABLE VI

STATISTICALLY SIGNIFICANT ASSOCIATIONS IN ADULTS

\begin{tabular}{|c|c|c|c|c|}
\hline \multicolumn{3}{|c|}{ Defects Associated } & $P\left(\chi^{2}\right)$ & $\begin{array}{l}\text { Tschuprow's } \\
\text { Coefficient }\end{array}$ \\
\hline \multirow{4}{*}{$\begin{array}{l}\text { Visual Acuity } \\
\text { and }\end{array}$} & Convergence & . & $<0.01$ & $0 \cdot 14$ \\
\hline & Heterophoria, vert & hear & $<0.01$ & $0 \cdot 17$ \\
\hline & Binocular Vision & . & $<0.01$ & $0 \cdot 14$ \\
\hline & Dark Adaptation & . & $<0.01$ & $0 \cdot 12$ \\
\hline \multicolumn{3}{|c|}{ Convergence and Heterophoria, lateral near } & $<0.02$ & $0 \cdot 11$ \\
\hline
\end{tabular}

\section{Discussion}

(1) Comparison of INCIDENCE OF Defects in CHILdRen AND Adults.-Amongst the visual functions, binocular vision and colour vision are known to be uninfluenced by age, whilst all the others are affected, some markedly. The present study bears out that the capacity for binocular vision is not influenced by age; the distinctly lower incidence of colour anomaly recorded for adults as compared with children is readily explicable, since the Post Office personnel have to rely on colour sense to a considerable extent, and an element of selfselection appears to have come into play.* The incidence of defects in other visual functions shows a considerable increase in adults as compared with children, but only visual acuity without glasses, accommodation, and dark adaptation (all of which have been studied for the different age groups in men) show a significant progressive increase in the four adult age groups investigated. It may be noted that the comparison between children and adults was somewhat weighted in favour of the adults, for they had undergone some occupational selection, whereas only children with extreme anomalies who would be attending classes for the partially sighted had been left out.

Clinically, the progressive deterioration in visual acuity and accommodation with age is readily compensated by the use of lenses. The increase in the incidence of defects in convergence-even when allowance is made for a lower norm in adult men-is apparently due to the same mechanism as that which produces an increase in the incidence of defects of muscle balance, i.e. a failure of muscle action. The capacity for dark adaptation declines steadily with age, probably because of the decrease in size of the dark-adapted pupil. A practical application of these findings is that (excluding binocular vision and colour vision) the incidence of defects in visual functions increases steadily over the years. A child with normal

\footnotetext{
* One of the Post Office employees volunteered the statement that in joining up cables of different colours he gets a mate to check the colour, as he knows his own colour discrimination to be unreliable.
}

visual functions may, therefore, still develop anomalies in later life; a child with anomalies is unlikely to improve. Not only the child who may become anomalous, but the child who is already anomalous, is missed in tests which are limited to the assessment of central visual acuity.

(2) The Fully Normal Child and Adult.-Some 70 per cent. of children have normal unaided visual acuity, but only about 50 per cent. of children are normal if all. the different visual functions are considered, for about 30 per cent. of those who pass as normal on tests for visual acuity, fail to pass on the other tests. The proportion of adult men who are fully normal is considerably less than the proportion of children: only about 60 per cent. of adult men have normal unaided visual acuity, and well over half of these fail on the other tests, so that only about 30 per cent. of men are fully normal.

\section{(3) The Anomalous Child}

(a) The Child with (Unaided) Normal Visual Acuity.On the available evidence, amongst 100 children with normal visual acuity, 31 would have some forty anomalies between them. Eleven would be anomalous on colour vision alone. The different varieties of muscle imbalance would contribute twelve anomalies, and these are essentially amenable to treatment; owing to the frequent association of one element of imbalance with another this means that eight out of the 31 children could be treated. The possibility of treating the remaining anomalies is indefinite; general measures might conceivably help with convergence, accommodation, and dark adaptation, but only exceptionally would remedial measures help the child (there would be only one in our hypothetical sample of 31 anomalous children) with no binocular vision. In broad terms there seems to be scope for therapeutic measures for about half of the 30 per cent. or so of children in whom normal visual acuity is associated with anomalies of other visual functions.

(b) The Child with (Unaided) Subnormal Visual Acuity.-The considerable incidence of defects in the different visual functions in these children shows how little can be expected from correcting glasses in reducing anomalies in visual functions other than visual acuity, which itself is readily corrected. The possibility of therapeutic measures seems to be greater here, as about half of these defects are contributed by errors in muscle balance. The clearly irremediable error due to colour anomalies - only contributes about one-tenth of the total of defects, and affects one-fifth of the children with anomalies. 
(4) The Anomalous Adult

(a) The Adult with (Unaided) Normal Visual Acuity.-The frequency of anomalies in the different functions, taking them as a whole, is more than twice as high in adults as in children. The proportion of remediable and possibly remediable defects is higher in adults than in children, for anomalies in muscle balance-presumably remediablepreponderate.

(b) The Adult with (Unaided) Subnormal Visual Acuity.-As with children, there is a greater incidence of anomalies of the other visual functions. Again as with children, the excess is possibly remediable, since it is due to a higher incidence of errors of muscle balance.

(5) Clinical Implications.-The salient facts brought out by the present investigations are these:

(i) About 70 per cent. of children of schoolleaving age have unaided normal visual acuity in the two eyes. Almost a third of these show anomalies in in the other visual functions. Anomalies in colour vision with their irremediable consequences constitute about a quarter of the defects. Lack of stereoscopic vision is uncommon, but anomalies in muscle balance, convergence, accommodation, and dark adaptation are not infrequent.

(ii) About 60 per cent. of adult men have unaided normal visual acuity, but the incidence of anomalies of other visual functions, excepting colour vision and binocular vision, is considerably higher than in children. (This higher incidence takes into account the normal physiological decrease in capacity ,for convergence, accommodation, and dark adaptation. For muscle balance the same criteria were used as for children).

The adult man who finds that his distance vision and his capacity for near work are failing, has ready recourse to glasses, which largely overcome these disabilities. He knows that colour defects are irremediable, and both by official action and by self-selection certain occupations are barred to such men. Decrease in the capacity for dark adaptation is only exceptionally sufficient to impose a definite handicap. It is with the heterophorias, poor convergence, and exceptionally with poor binocular vision, that real, though ill-recognized problems, may arise. The considerable increase in the incidence of the heterophorias with age presents a double clinical difficulty. The ophthalmologist has to assess firstly whether the heterophorias, as arbitrarily defined in the present study, produce symptoms, and secondly whether they are amenable to treatment.
(6) Significance of Visual Defects under Field ConDITIONS.-In 1953, some 5 years after the original survey, a follow-up of the children and adults previously examined was attempted. Adequate data could be obtained on 320 of the 654 children originally examined, and on 354 of the 501 men. Information was obtained on the children's progress after leaving school and this was set against the findings on their eyes. An assessment of the men's efficiency at their work was likewise set against their ocular record.

(a) Follow-up of School Children.-In the 5 years or so that had elapsed most of the children had entered industry, and towards the end of this period most of the boys had been drafted to the Services. It was thus possible to assess how their careers had shaped: some had obviously progressed in their work (having risen, for example, from junior clerkships to more responsible posts-Group 1), and many more had maintained their positions (staying as apprentices to compositors, continuing at technical schools, holding their own at office work or in a factory, and so on-Group 2). As against these two groups of children whose careers were essentially satisfactory, others had poorer records: some had shown little tendency to engage in any but menial or "blind-alley" occupations (Group 3), some had changed their occupation frequently (Group 4), and a few seemed to be drifting aimlessly (Group 5). These five groups and the ocular findings are shown in Table VII (opposite), which shows that a poor visual score is not a significantly adverse factor in the shaping of a career, but that other factors obviously have a more determining effect. It should, however, be noted that this assessment could not be made on the basis of specific visual requirements for specific tasks.

(b) Follow-up of Post Office Engineers.-Of the total of 354 men for whom follow-up information was available, thirteen were excluded from further consideration as they fell into two small occupational groups. The remaining 341 men were employed on three distinct types of work. The visual requirements of two groups were considered to be very much the same, whilst those of the third group were thought to be rather less stringent. The visual records of these workers were set against the rating each had obtained for efficiency at his work, as shown in Table VIII (opposite).

It will be seen that the group with only moderate efficiency showed a rather greater incidence of visual defects than was found in those with higher degrees of efficiency. The differences observed were not, however, large enough to be statistically significant; 
TABLE VII

FOLLOW-UP ON CAREERS 5 YEARS AFTER LEAVING SCHOOL RELATED TO PREVIOUS OCULAR FINDINGS IN SCHOOL CHILDREN

\begin{tabular}{|c|c|c|c|c|c|c|c|c|}
\hline & \multirow{4}{*}{ Sex } & & \multicolumn{6}{|c|}{ Careers } \\
\hline & & & \multicolumn{3}{|c|}{ Satisfactory (Groups 1 and 2) } & \multicolumn{3}{|c|}{ Less Satisfactory (Groups 3, 4, and 5) } \\
\hline & & & \multicolumn{2}{|c|}{ Percentage Visual Defects* at School } & \multirow{2}{*}{$\begin{array}{l}\text { Total No. } \\
\text { Children }\end{array}$} & \multicolumn{2}{|c|}{ Percentage Visual Defects* at School } & \multirow{2}{*}{$\begin{array}{l}\text { Total No. } \\
\text { Children }\end{array}$} \\
\hline & & & $\begin{array}{c}\text { One or Two } \\
\text { Functions }\end{array}$ & $\begin{array}{l}\text { Three or More } \\
\text { Functions }\end{array}$ & & $\begin{array}{c}\text { One or Two } \\
\text { Functions }\end{array}$ & $\begin{array}{l}\text { Three or More } \\
\text { Functions }\end{array}$ & \\
\hline Male .. & . & . & 29 & 7 & 126 & 21 & 13 & 47 \\
\hline Female & .. & . & 42 & 3 & 94 & 36 & 6 & 53 \\
\hline Total & . & .. & 35 & 5 & 220 & 29 & 9 & 100 \\
\hline
\end{tabular}

* The same criteria were used as before, except that 6/9 vision was regarded as normal.

The total incidence of defects is about the same in both these groups. The excess of those with more than three defective functions in the less satisfactory group is not statistically significant.

TABLE VIII

FOLLOW-UP ON GRADING OF EFFICIENCY AT WORK 5 YEARS AFTER OCULAR SURVEY OF POST OFFICE ENGINEERS

\begin{tabular}{|c|c|c|c|c|c|}
\hline \multirow{3}{*}{ Visual Requirements } & \multirow{3}{*}{ Class of Work } & \multicolumn{4}{|c|}{ Efficiency } \\
\hline & & \multicolumn{2}{|c|}{ Very Good and Good } & \multicolumn{2}{|r|}{ Moderate } \\
\hline & & $\begin{array}{l}\text { No. in } \\
\text { Group }\end{array}$ & $\begin{array}{l}\text { Percentage showing } \\
\text { Defect in one or } \\
\text { more required Visual } \\
\text { Functions }\end{array}$ & $\begin{array}{l}\text { No. in } \\
\text { Group }\end{array}$ & $\begin{array}{l}\text { Percentage showing } \\
\text { Defect in one or } \\
\text { more required Visual } \\
\text { Functions }\end{array}$ \\
\hline $\begin{array}{l}\text { Good visual acuity }{ }^{1} \\
\text { Stereoscopic vision } \\
\text { Normal colour vision }\end{array}$ & $\begin{array}{l}\text { (1) Auto and 2VF equipment } \\
\text { maintenance } \\
\text { VF Telegraph maintenance, } \\
\text { general wiring duties, } \\
\text { including jumpering }\end{array}$ & \multirow[t]{2}{*}{$122\}$} & \multirow[t]{2}{*}{97} & \multirow{2}{*}{\}$_{35}$} & \multirow[t]{2}{*}{$\because 18$} \\
\hline $\begin{array}{l}\text { Good visual acuity } \\
\text { Stereoscopic vision }{ }^{2} \\
\text { Normal colour vision }\end{array}$ & $\begin{array}{l}\text { (2) Exchange maintenance } \\
\text { Transmission equipment } \\
\text { maintenance } \\
\text { Power, stores, and work- } \\
\text { shop duties }\end{array}$ & & & & \\
\hline $\begin{array}{l}\text { Good visual acuity } \\
\text { Muscle balance }\end{array}$ & $\begin{array}{l}\text { (3) Test Desk } \\
\text { Lining-up and Control } \\
\text { duties } \\
\text { Survey and Clerical work }\end{array}$ & 50 & 16 & 5 & 40 \\
\hline
\end{tabular}

These differences are not large enough to be statistically significant. Their consistency does, however, suggest that visual defects played some part in producing efficiency graded as only moderate.

their consistency suggests that they do play a part, though clearly there are other factors.

(7) Some Tentative Conclusions.-The findings justify the following observations:

(i) There is no case for extending the routine medical examination at school to cover visual functions other than central acuity.

(ii) There is a case for assessing specific visual functions for specific tasks.

(iii) The requirements of specific industries need to be established. Only a few have any clear criteria, though there is much to suggest that industrial efficiency and individual contentment call for such requirements to be clearly known.

(iv) An investigation into the possibilities of ameliorating visual defects other than those of central visual acuity in school children is warranted. Nothing can be done for congenital colour defect, or for children lacking binocular vision, but knowledge on other matters is needed. The practical significance of defective dark adaptation remains to be assessed. The nature and significance of anomalies of accommodation, convergence, and muscle balance are ill-understood. As these functions are all largely muscular in type and.do not appear to be markedly correlated with visual acuity, there is a possibility 
that they are determined by systemic rather than local factors, though an ocular factor is suggested by the greater incidence of such anomalies in children with unaided subnormal vision. The relative significance of systemic and ocular factors needs to be determined, as also whether anomalies of muscle action cause disabilities, and whether they are amenable to treatment. Information so gained in children should be invaluable in assessing the importance to be attached to the considerably greater incidence of such anomalies in the adult population.

\section{SUMMARY}

(1) The different functions of vision-central visual acuity, accommodation, convergence, muscle balance, binocular vision, colour vision, and dark adaptation-were tested in 654 children aged 12 to 14 years, and in 501 men aged 21 to 40 years.

(2) Conventional criteria of normality were adopted; these were largely confirmed by the distribution curves obtained in this material.

(3) In children, 74.9 per cent. were found to have normal visual acuity, but only $52 \cdot 1$ per cent. were normal in all respects. In adults, $64 \cdot 1$ per cent. had normal visual acuity, and $28 \cdot 8$ per cent. were normal in all respects.

(4) In both children and adults the incidence of defects other than those of visual acuity was considerably higher in those whose central visual acuity was subnormal.

(5) Except for colour vision and stereoscopic vision, the incidence of anomalies was found to increase markedly with age. In consequence, whilst relatively few children showed more than one defect, the incidence of multiple defects in adults was considerable.

(6) There is some evidence that both systemic and local factors are responsible for anomalies other than those of central visual acuity, and for the increased incidence of some anomalies with age.

(7) The functional significance of the relatively unconsidered anomalies, especially those of muscle balance and stereoscopic vision, and whether these anomalies are remediable, remains to be assessed.

(8) A follow-up after 5 years of the school children examined offered no suggestion that anomalies in visual functions had significantly affected their careers, though owing to the large number of occupations involved it was not possible to relate this inquiry to specific occupations. A similar follow-up inquiry amongst the adults examined could be related to specific tasks; here it appeared that there might be some relationship between efficiency at work and the visual capacity required for particular tasks.

(9) The need for specific visual standards for different occupations is indicated.

Our thanks are due to Dr. F. R. Dennison, Medical Officer of Health of West Ham, and to his Council and his staff, as also to the late Dr. C. W. Roberts, Deputy Treasury Medical Officer (Post Office Branch), and his staff for kindly making this investigation possible.

We are indebted to Mr. R. A. Burn, Miss Joan Haythorne, and Mr. G. C. Pritchard for making the laborious examinations and records for this study. Miss Betty Christie and Miss S. K. Reddy carried out the haemoglobin estimations and the tests for dark adaptation. Mr. L. H. Savin helped with advice. The cost of the investigation was defrayed by grants made by the Institute of Ophthalmology for Research and Teaching (Royal Eye Hospital) and by the Treasury.

\section{APPENDIX}

\section{Functions Tested and Methods Employed}

\section{CHILDREN}

(1) Visual Acuity.-The standard Snellen test type was used at $6 \mathrm{~m}$., illuminated by two 60-watt Tungsten lamps with reflectors placed $1 \mathrm{ft}$. from the board.

Each eye was tested separately and both eyes together with and without glasses. Visual acuity was recorded according to the lowest line of which all the letters were read correctly plus any letters correctly read in the next line. If more than half the letters were read correctly that line was taken as the measure of visual acuity for analysis.

Children without glasses and having less than 6/9 vision in one eye were refracted and tested for the other visual functions with glasses if prescribed. With correction it was exceptional for a child not to have full vision.

(2) Accommodation.-The Livingston binocular gauge was used and each eye was tested separately. The end-point was taken not at inability to read but at the onset of subjective blurring of type.

(3) CONVERGENCE.-The Livingston binocular gauge was used, taking as end-point the objective deviation of the corneal reflexes. 
(4) Muscle Balance.-For near vision the Maddox wing was used and for distance the Maddox rod at $6 \mathrm{~m}$. fixing with each eye in turn.

(5) Binocular Vision.-This was assessed on the synoptophore using the following criteria:

Simultaneous Macular Perception.-Ability. to superimpose large-sized simultaneous macular perception slides (Lion and Cage. Clement Clarke, H.11-12).

Fusion.-Ability to fuse large fusion slides (Rabbit with flowers and tail. Clement Clarke, F.3-4).

Stereoscopic Vision.-Eccentric rings (Clement Clarke, D.1-2) were used as the minimum requirement for stereoscopic vision. In addition 425 children out of the total were tested for degree of stereoscopic vision using the Livingston rotating stereogram slides in the synoptophore.

(6) Colour Vision.-The Ishihara pseudoisochromatic plates, 6th edition (1932) were used. The illumination was designed to approach as closely as possible to the International Commission on Illumination's "illuminant C", recommended by Hardy (1945). This consisted of a lamp and blue glass filter giving an illumination of 50 foot-candles on the plates with an equivalent colour temperature of $7,500^{\circ} \mathrm{K}$.

Dichromatism was diagnosed when the subject consistently gave the dichromatic reading for two or more of the Plates 2-5. The type of dichromatic defect was assessed in Plates 12 and 13; protanopes read Plate 12 as 6 and Plate 13 as 2, while deuteranopes read Plate 12 as 2 and Plate 13 as 4 .

Anomalous trichromatism was diagnosed when the subject fell short of frank dichromatism and yet made at least one mistake in Plates 2-5 with each eye.
(7) Dark Adaptation.--This was measured with the Crookes's adaptometer by measuring the "final rod threshold", that is, the minimal amount of light detected after complete, or nearly complete, dark adaptation. At intervals of about 15 minutes, groups of three or four subjects entered a dark room directly from their work with no previous dark adaptation. After at least 35 minutes, each subject was placed at the instrument, the illumination increased and decreased and the value recorded at which the light just disappeared. This was repeated over a minute or two until consistent readings were obtained. The three or four subjects in each group were tested in turn and then tested a second time in the same order. The second value was taken as a measure of the subject's capacity for dark adaptation. The techniques employed were those given by Robertson and Yudkin (1944).

(8) Haemoglobin.- - This was estimated by the alkaline haematin method. From the pricked fore-finger, $0.05 \mathrm{ml}$. blood was accurately taken and mixed into exactly $5 \mathrm{ml} .0 \cdot 1 \mathrm{~N}$ caustic soda solution. The tubes containing the mixture were heated in a water bath and then the intensity of colour, referred to the Gibson-Harrison artificial standard solution, was measured in a photo-electric colorimeter (Clegg and King, 1942).

\section{ADULTS}

The methods of examination used in adults were the same as those for children, except that no haemoglobin tests were carried out.

\section{REFERENCES}

Clegg, J. W., and King, E. J. (1942). Brit. med. J., 2, 329.

Hardy, Le G. H. (1945). Arch. Ophthal. (Chicago), 34, 278 Robertson, G. W., and Yudkin, J. (1944). J. Physiol. (Lond.), 103, 1. 